\title{
TOLTERODINE IMPROVES QUALITY OF LIFE IN PATIENTS WITH AN OVERACTIVE BLADDER, WITH OR WITHOUT URINARY INCONTINENCE: A PROSPECTIVE MULTICENTER STUDY
}

\author{
F. Mantovani, G. Bozzini, P. Acquati, \\ S.S. Di Pierro, M.G.Spinelli, F. Rocco
}

Department of Urology, University of Milan, IRCCS Ospedale Maggiore Policlinico di Milano, Milan Italy

Key words:

Tolterodine, quality of life, overactive bladder

\section{SUMMARY}

AIMS: In order to analyse the effect of tolterodine on the Quality of life (QoL) of patients with overactive bladder (OB) we conducted a prospective multicentre clinical study.

MATERIALS AND METHODS: Subjects were questioned at entry and 4, 12 and 24 weeks later about the number of micturitions and incontinent and urgency episodes/day, using a micturition diary. The mean volume voided per micturition and the number of pads used per day was also recorded. The QoL was measured using the Kings Health Questionnaire (KHQ) and the Incontinence Impact Questionnaire (IIQ). A total of 179 patients entered the study: 59 dropped out (4 due to lack of efficacy, 10 due to adverse events, 25 because of lack of interest in the study/other reason and 20 were lost at follow up), leaving 120 patients for analysis. One hundred and eight patients (90\%) were female, their mean age was 56.5 years (SD 11.2); 87 had never received treatment for OB/UI (80.6\%) and their mean weight was $70.0 \mathrm{Kg}$ (SD 12.7).

RESULTS: The mean number of micturitions/day was 9.3 at trial entry and it decreased to 6.8 by the end of the study. The corresponding values for the number of urge episodes, incontinence episodes and number of pads used per day were 3.5, 2.7 and 1.2 and $0.8,0.9$ and 0.4 respectively. The mean volume voided per micturition increased from $146 \mathrm{ml}$. to $178 \mathrm{ml}$. All the differences between trial entry and end of study values were statistically significant $(\mathrm{p}<0.05)$. Considering the results of the KHQ, the values of all the different areas/domini (?) decreased markedly and in a statistically significant way between the start of treatment and the end of study evaluations. Similar findings emerged when we considered values of the IIQ. The decrease was constant and marked during the first three months and remained constant thereafter.

CONCLUSIONS: This study, conducted in a population of subjects with dry and wet $\mathrm{OB}$, shows that tolterodine given for six months lowers the frequency of urgency episodes and incontinence episodes without troublesome adverse effects. These clinical effects are mirrored in the QOL, KHQ and IIQ questionnaire scores, which improved by about $50 \%$ over the same period. 


\section{INTRODUCTION}

Overactive bladder (OB) with or without urinary incontinence (UI) is a condition that considerably affects the quality of life (QoL). It is important to asses the effect of any treatment in terms of improving QoL (17).

Tolterodine (8) has documented efficacy in lowering the frequency of UI. Randomized trials have indicated that it improves micturition diary variables in patients with $\mathrm{OB}$ with or without UI, and is tolerated better than other muscarinic receptor antagonists both given b.i.d. or in a single dose (9-11). Improvements in patients' perception of urgency symptoms has also been reported during treatment with tolterodine (12-15).

In order to analyse the effect of tolterodine on the Quality of Life (QoL) of patients with overactive bladder (OB) with or without UI, we conducted this prospective multicenter clinical trial.

\section{MATERIALS AND METHODS}

Those eligible for the study were men and women aged $18-75$ years with urinary frequency (eight or more micturition/24 hours) and urgency with or without UI, and negative urinocolture, consecutively observed in 27 teaching and general hospitals.

Micturition diaries were completed before starting treatment and were used to quantify the baseline urinary frequency, urge and incontinence episodes.
Exclusion criteria were any severe liver, cardiovascular, neurological and gastrointestinal disease, diabetes, contraindications to the use of muscarinic receptor antagonists and known or suspected hypersensitivity to tolterodine.

The research protocol was approved independently by the ethics committees of individual centres, which established the procedure for obtaining informed consent.

All study subjects gave written informed consent.

After a two week run-in period, all subjects took tolterodine $2 \mathrm{mg}$ bis in die per os for 24 weeks.

Subjects were questioned at entry 4,12 and 24 weeks later about the number of micturition, incontinence and urgency episodes/day, using a micturition diary. The mean volume voided per micturition and the number of pads used per day was also recorded. The QoL was measured using the Kings Health Questionnaire (KHQ) (16) and the Incontinence Impact Questionnaire (IIQ) (17). Any adverse events were recorded at each visit.

Descriptive statistics such as the mean, standard deviation and median were used to describe the summary measures of clinical variables and of the KHQ and IIQ. Differences between basal and final values were tested using the T-test adjusted for multiple tests.

\section{RESULTS}

A total of 179 patients entered the 
study: 59 dropped out (4 due to lack of efficacy, 10 due to adverse events, 25 because of lack of interest on the study and other reasons and 20 were lost during follow up), leaving 120 patients for analysis. One hundred and eight patients (90\%) were female, their mean age was 56.5 years (SD $11.2)$; 87 had never received treatment for OB and UI (72.5\%) and their mean weight was $70.0 \mathrm{Kg}$ (SD 12.7).

During the run-in period no difference emerged in score values of different KHQ and IIQ areas/domini (?). For example the mean values were $15.2,17.4,26.3$ and 14.8 at the begining and 15.0, 17.0, 25.4 and 14.0 at the end of the run-in period for the IIQ activity, travel, social and emotional areas/domini (?) respectively.

Table 1 shows the clinical effect of the treatment. The mean number of micturiotions/day was 9.3 at trial entry and it decreased to 6.8 by the end of the study. The corresponding values for the number of urge episodes, incontinence episodes and pads used per day were 3.5, 2.7,1.2 and 0.8, 0.9, 0.4 respectively. The mean volume voided per micturition increased from $146 \mathrm{ml}$ to $178 \mathrm{ml}$. All the differences between trial entry and end of study values were statistically significant $(\mathrm{p}<0.05)$.

The mean change in the number of urge and incontinence episodes is reported in Fig.1. A sharp reduction was reached after 1 month of treatment and was maintained for the following months.

Table 2 presents the result of the KHQ, the values of all the different areas/domini(?) decreased markedly and in a statistically significant way, between the beginning of the treatment and the end of study evaluations. Similar findings emerged when we considered the IIQ values (Table 2 ). The decrease was constant and marked during the first three months and remained constant thereafter (Fig.2 and 3).

We also analysed the effect of tolterodine on the number of micturitions, incontinece and urge episodes/day, the mean volume voided per micturition and the number of pads used per day, using KHQ and IIQ according to/in strata of (?) sex. The results were largely similar for both sexes and in patients who had or had never been treated for this condition (data not shown). Ten patients (5.5\%) patients dropped out because of poor tolerance, 7 reported a dry mouth.

\section{DISCUSSION}

Tolterodine improved the clinical symptoms and the QoL, as measured by the KHQ and the IIQ, over a six month period in subjects with OB, with or without UI. The effect of the treatment was similar in males and females and in subjects who had or had never been treated for OB.

The choice of the questionnaires used for the evaluation of the QoL should be briefly discussed. Several disease-specific questionnaires have been developed for patients with OB and UI. We chose the IIQ because it is the most commonly used one and has been adopted in routine clinical 
practice because of its brevity and ease of scoring. The KHQ is a useful, simple, brief development of the disease-specific questionnaires for UI.

In this study tolterodine improves both the clinical symptoms and the QoL indicators. This is consistent with previous data showing a direct relationship between improving clinical symptoms and the QoL of patients with OB with UI. For example, in a survey in North Carolina (18) accidental loss of urine was the best predictor of response to the IIQ. Similar results emerged in an Italian study showing a greater marked reduction in the QoL measured with the RANDShort form 12-Items Health Survey questionnaire in women with $\mathrm{OB}$ and UI than in women with only OB. In

Table 1 - Clinical symptoms at trial entry and at the end of the study

\begin{tabular}{lccc}
\hline & $\begin{array}{c}\text { Trial entry } \\
\text { Final visit }\end{array}$ & $\begin{array}{c}\text { Mean (SD) } \\
\text { Mean (SD) }\end{array}$ & P value \\
\hline Micturition/day & $9.29(3.3)$ & $6.78(2.5)$ & $<0.05$ \\
\hline Volume void per micturition (ml) & $146.02(55.73)$ & $178.25(64.23)$ & $<0.05$ \\
\hline Urge episodes/day & $3.45(3.85)$ & $0.84(1.56)$ & $<0.05$ \\
\hline Incontinence episodes/day & $2.68(3.32)$ & $0.92(1.87)$ & $<0.05$
\end{tabular}

Fig. 1 - Mean change in the number of urge and incontinence episodes
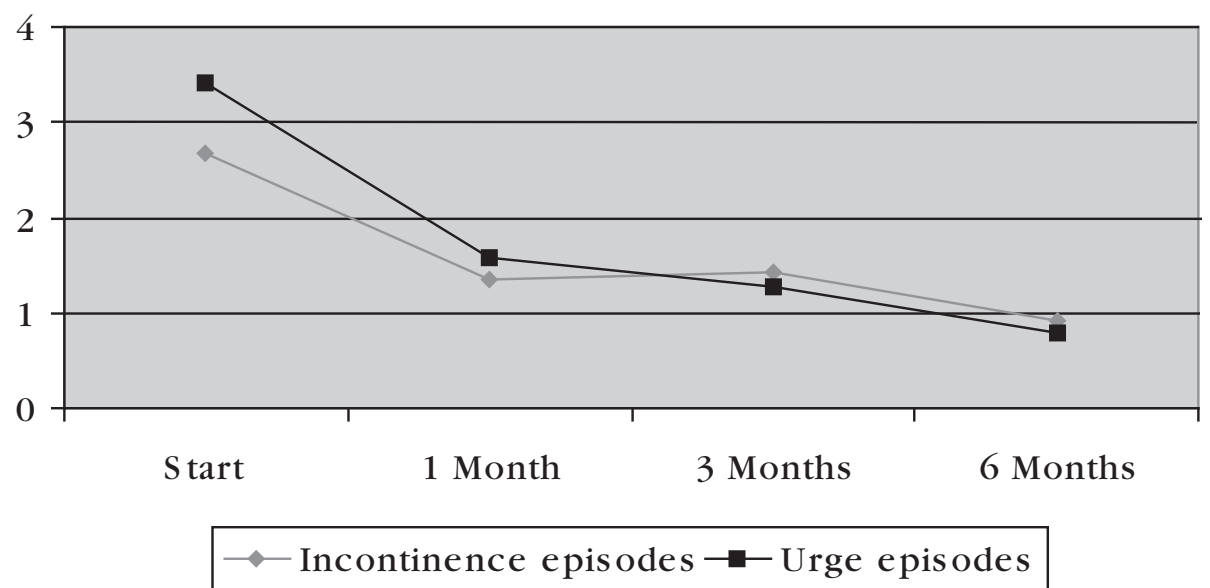
Table 2 - Results in QoL. Questionnaires at start of treatment and at the end of the study

\section{Start of treatment Final visit P value Mean (SD) Mean (SD)}

\section{KHQ}

General health

$2.84(0.88)$

$2.51(0.78) \quad<0.05$

Incontinence impact

$3.10(0.82)$

$2.26(0.90) \quad<0.05$

Symptom severity

$13.35(4.22)$

$8.52(3.84)<0.05$

Role limitations

$5.16(1.90)$

$3.55(1.74) \quad<0.05$

Physical limitations

$5.67(1.83)$

$3.81(1.80)<0.05$

Social limitations

4.98 (1.98)

$3.25(1.65)<0.05$

Emotion

$8.01(2.76)$

$5.39(2.49)<0.05$

Energy/Vitality

$5.05(1.67)$

$3.53(1.37)<0.05$

Severity

$10.36(3.20)$

$7.68(3.24)$

$<0.05$

the Italian study OB/UI had more impact on the QoL when urinary symptoms were more severe (19). This suggests that the severity of clinical symptoms diminishes the QoL.

Another interesting finding of this study is that the effect of tolterodine was observed after one month of treatment, remaining constant from there on. This confirms clinical data and suggests that the efficacy of treatments on clinical symptoms and the QoL should be evaluated after at least one month.

\section{CONCLUSIONS}

This study conducted in a population of subjects with dry and wet OB, shows that tolterodine given for six months decreases the frequency of urge and incontinence episodes. This clinical effects are mirrored in the QoL, KHQ and IIQ questionnaire score, which improves by about 50\% over the same period.

It is worth noting that the improvement of clinical symptoms and of the QoL was achieved with no ma- 
Fig. 2 - Effect on QoL according to KHQ

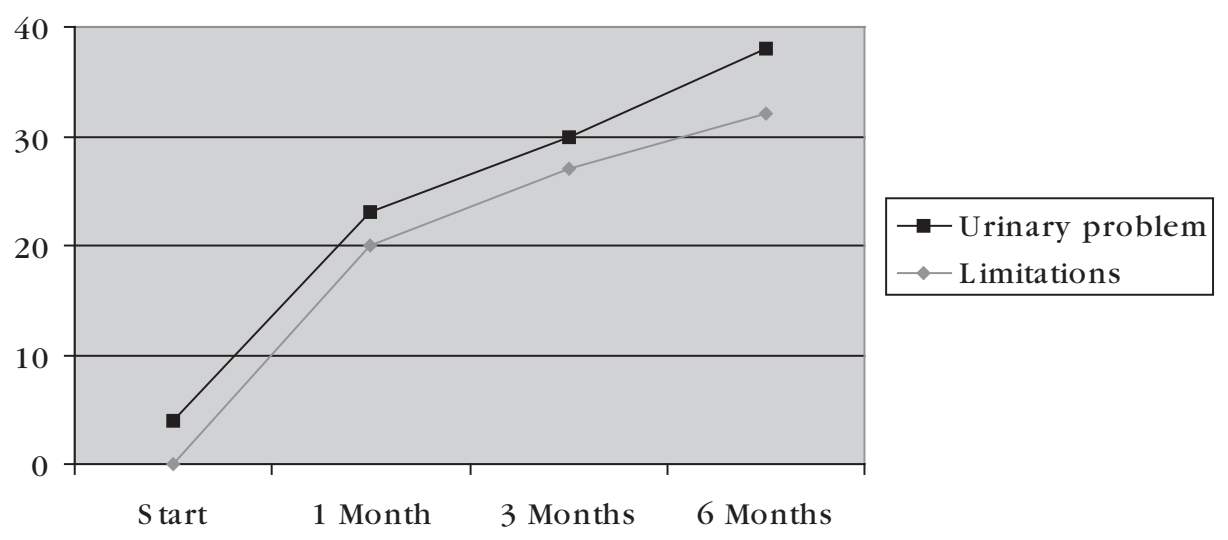

Fig. 3 - Effect on QoL according to IIQ

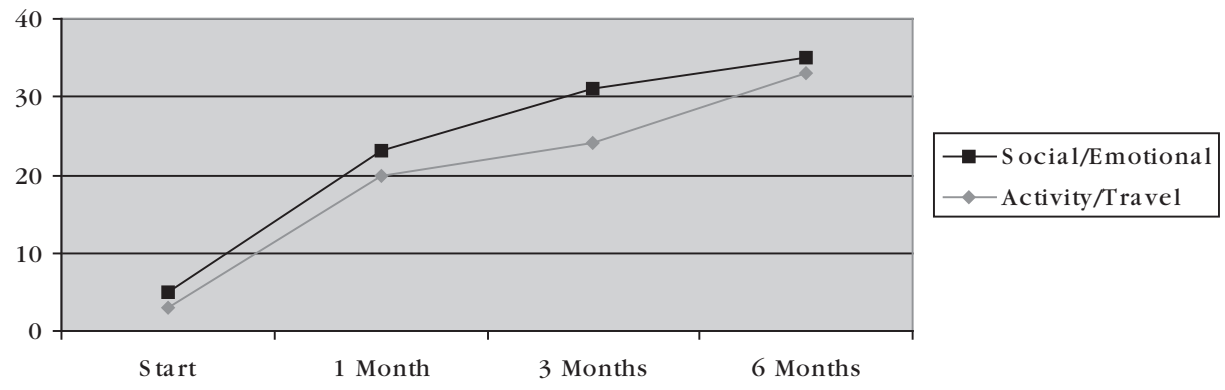

jor adverse effects. Only 10 patients dropped out on account of poor tolerance and less than 5\% reported a dry mouth. These proportions are similar to those reported in previous trials and lower than those reported for other muscarinic receptor antagonists (20). 
For correspondence:

Franco Mantovani, M.D.

Department of Urology

IRCCS Ospedale Maggiore Policlinico

Via della Commenda, 15

20122 Milan Italy

Phone +3902 55034502

Fax +3902 55030584

uropoli@unimi.it

matteogiuliospinelli@gmail.com

\section{REFERENCES}

1 - FITZGERALD M.P., KENTON K., SHOTT S., BRUBAKER L. : (2001) Responsiveness of quality of life measurements to change after reconstructive pelvic surgery.

Am J Obstet Gynecol 185: 20-24.

2 - SHAW C. :

(2001) A review of the psychosocial predictors of help-seeking behaviour and impact on quality of life in people with urinary incontinence.

J Clin Nurs 10: 15-24.

3 - WOODMAN P.J., MISKO C.A., FISCHER J.R. : (2001) The use of short-form quality of life questionnaires to measure the impact of imipramine on women with urge incontinence.

Int Urogynecol J Pelvic Floor Disfunct 12: 312-315.

4 - SIMEONOVA Z., MILSOM I., KULLENDORFF A.M., MOLANDER U., BENGTSSON C. :

(1999) The prevalence of urinary incontinence and its influence on the quality of life in women from an urban Swedish population.

Acta Obstet Gynecol Scand Jul 78(6): 546-551.

5 - GRIMBY A., MILSOM I., MOLANDER U., WIKLUND I., EKELUND P. : (1993) The influence of urinary incontinence on the quality of life of elderly women.

Age Aging 22: 82-89.

6 - HAGGLUND D., WALKER-ENGSTROM M.L., LARSSON G., LEPPERT J. : (2001) Quality of life and seeking help in women with urinary incontinence. Acta Obstet Gynecol Scand Nov 80(11): 1051-5. 
7 - KELLEHER C.J., CARDOZO L.D., TOOZS-HOBSON P.M. : (1995) Quality of life and urinary incontinence.

Curr Opin Obstet Gynecol 7: 404-8.

8 - NILVEBRANT L., ANDERSSON K.E., GILLBERG P.G. et al. : (1997) Tolterodine a new bladder selective antimuscarinic agent. Eur J Pharmacol 327: 195-207.

9 - CLEMETT D., JARVIS B. : (2001) Tolterodine: a review of its use in the treatment of overactive bladder. Drugs \& Aging 18: 277-304.

10 - HARVEY M.A., BAKER K., WELLS G.A. : (2001) Tolterodine versus oxybutynin in the treatment of urge urinary incontinence: a meta-analysis.

Am J Obstet Gynecol 185: 56-61.

11 - VAN KERREBROECK P., KREDER K., JONAS U., ZINNER N., WEIN A. : (2001) On behalf of the Tolterodine Study Group. Tolterodine once-daily: superior efficacy and tolerability in the treatment of the overactive bladder. Urol 57: 414-421.

12 - KOBELT G., KIRCHBERGER I., MALONE-LEE J. : (1999) Quality of life aspects of the overactive bladder and the effect of treatment with tolterodine.

BJU Int 81: 583-590.

13 - KELLEHER C.J., KREDER K.J., PLEIL A.M., BURGESS S.M., REESE P.R. : (2002) Long term health-related quality of life of patient receiving extendedrelease tolterodine for overactive bladder.

Am J Manag Care 8: 5616-30.

14 - WEIN A.J., ROVNER E.S. : (1999) The overactive bladder: an overview for primary care bealth providers.

Int J Fertil 44: 56-66.

15 - Payne C.K. : (1998) Epidemiology, pathophysiology and evaluation of urinary incontinence and overactive bladder. Urol 51: 3-10. 
16 - KELLEHER C.J., CARDOZO L.D., KHULLAR V., SALVATORE S. : A new questionnaire to assess the quality of life of urinary incontinent women.

Br J Obstet Gynecol

17 - UEBERSAX J.S., WYMAN J.F., SHUMAKER S.A., MCCLISH D.K., FANTL J.A. and the CONTINENCE PROGRAM FOR WOMEN RESEARCH GROUP : (1995) Short Forms to assess life quality and symptoms distress for urinary incontinence in women: the incontinence impact questionnaire and the urogenital distress inventory.

Neurourol Urodyn 14: 131-139.

18 - ROBINSON D., PEARCE K.F., PREISSER J.S., DUGAN E., SUGGS P.K., COHEN S.J. :

(1998) Relationship between patient reports of urinary incontinence symptoms and quality of life measures.

Obstet Gynecol 91: 224-8.

19 - CHIAFFARINO F., PARAZZINI F., LAVEZZARI M., GIAMBANCO V. : On behalf of Gruppo Interdisciplinare di Studio Incontinenza Urinaria (GISIU). (2003) Impact of urinary incontinence and overactive bladder on quality of life.

Eur Urol 303: 1-4

20 - SAMUELSSON E., VICTOR A., TIBBLIN G. :

(1997) A population study of urinary incontinence and nocturia among women aged 20-59 years. Prevalence, well-being and wish to treatment. Acta Obstet Gynacol Scand 76: 74-80. 